\title{
Double Orifice Mitral Valve: An Incidental Finding
}

\author{
Bhavin Brahmbhatt, Nikunj Vaidhya, Vaibhav Jain, Mrinal Patel, Amit Mishra' \\ Departments of Cardiovascular and Thoracic Surgery and 'Pediatric Cardiovascular and Thoracic Surgery, U. N. Mehta Institute of Cardiology and Research \\ Center, (Affiliated to BJ Medical College), Ahmedabad, Gujarat, India
}

\section{Abstract}

A double orifice mitral valve (DOMV) represents a rare congenital malformation characterized by two valve orifices with two separate subvalvular apparatus. We present an interesting case of an asymptomatic 1 year and 8 months old male child with DOMV who successfully underwent surgery.

Keywords: Congenital heart disease, double orifice mitral valve, echocardiography, mitral valve

\section{INTRODUCTION}

A double orifice mitral valve (DOMV) is an uncommon anomaly that was first described by Greenfield in 1876. DOMV represents a rare congenital malformation characterized by two valve orifices with two separate subvalvular apparatus.

\section{Case Report}

We report a case of an asymptomatic 1 year and 8 months old male child, referred to our department by a pediatric cardiologist. His echocardiography finding suggestive of partial atrioventricular (AV) canal defect with DOMV with the small mitral annulus [Figure 1]. Tricuspid annulus was $14 \mathrm{~mm}$ whereas mitral annulus was $9 \mathrm{~mm}$.

During surgery, DOMV anatomy was assessed [Figure 2], the valve area was adequate for his body surface area without any regurgitation. At this moment, recognition of DOMV has no impact on the patient's management. It might, however, be of importance at the time of a further follow-up where he can develop regurgitation. The patient is on regular follow-up without any mitral valve regurgitation or stenosis for 6 months, and he is doing well.

\section{DISCUSSION}

A DOMV is an uncommon anomaly that was first described by Greenfield in 1876. ${ }^{[1]}$ DOMV represents a rare congenital malformation. Characterized by two valve orifices with two

\begin{tabular}{|l|l|}
\hline \multicolumn{3}{c|}{ Access this article online } \\
\hline Quick Response Code: & Website: \\
& \\
http://www.ijcva.com
\end{tabular}

separate subvalvular apparatus. ${ }^{[2,3]}$ The natural history of DOMV with intact AV septum is not known.

This case reveals the necessity of careful imaging of the mitral valve apparatus, not only in patients with AV septal

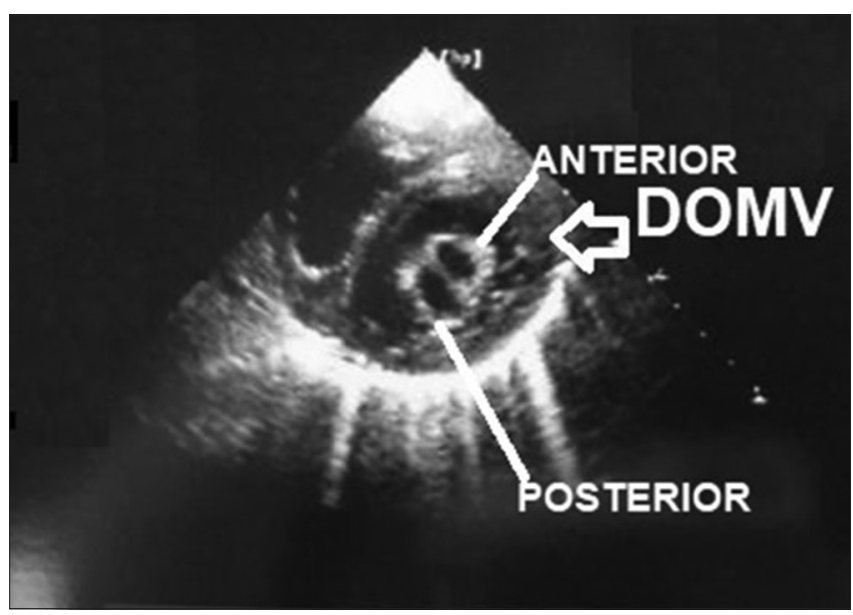

Figure 1: Parasternal short axis view at the level of the mitral valve demonstrating the two separate orifices of the double orifice mitral valve

Address for correspondence: Dr. Amit Mishra, Department of Pediatric Cardiovascular and Thoracic Surgery, U. N. Mehta Institute of Cardiology and Research Center, (Affiliated to BJ Medical College), Ahmedabad - 380 016, Gujarat, India E-mail:drmishraamit@gmail.com

This is an open access journal, and articles are distributed under the terms of the Creative Commons Attribution-NonCommercial-ShareAlike 4.0 License, which allows others to remix, tweak, and build upon the work non-commercially, as long as appropriate credit is given and the new creations are licensed under the identical terms.

For reprints contact: reprints@medknow.com

How to cite this article: Brahmbhatt B, Vaidhya N, Jain V, Patel M, Mishra A. Double orifice mitral valve: An incidental finding. Int J Cardiovasc Acad 2018;4:62-3. 


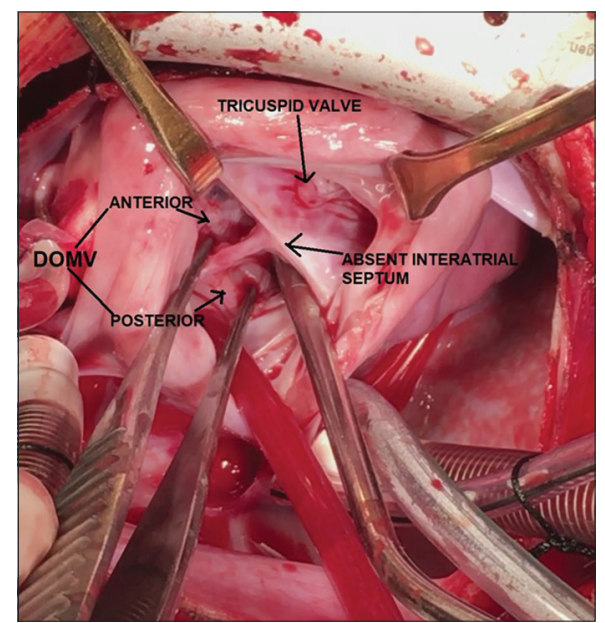

Figure 2: Operative finding

defects but also in patients with congenital left obstructive heart disease.

It is most often associated with AV septal defects (it has been found in as many as $4.9 \%-17.9 \%$ of cases in necropsy studies),${ }^{[4]}$ but may also be present together with other congenital heart defects such as left-sided obstructive lesions, ventricular septal defects, or cyanotic lesions. Rarely, patients with isolated DOMV are reported. However, even in the modern era of echocardiography DOMV often remains unrecognized. The hemodynamic impact of DOMV varies from a normally functioning valve to (less frequent) significant mitral regurgitation (with or without cleft) or stenosis. Surgical correction of DOMV is indicated in a minority of patients undergoing repair of associated lesions. However, these patients need regular follow-up to know any change in morphology and function of the left $\mathrm{AV}$ valve in the near future.

\section{Declaration of patient consent}

The authors certify that they have obtained all appropriate patient consent forms. In the form the patient(s) has/have given his/her/their consent for his/her/their images and other clinical information to be reported in the journal. The patients understand that their names and initials will not be published and due efforts will be made to conceal their identity, but anonymity cannot be guaranteed.

\section{Financial support and sponsorship}

Nil.

\section{Conflicts of interest}

There are no conflicts of interest.

\section{RefEREnCES}

1. Greenfield WS. Double mitral valve. Trans Pathol Soc London 1876;27:128-9.

2. Das BB, Pauliks LB, Knudson OA, Kirby S, Chan KC, Valdes-Cruz L, et al. Double-orifice mitral valve with intact atrioventricular septum: An echocardiographic study with anatomic and functional considerations. J Am Soc Echocardiogr 2005;18:231-6.

3. Zalzstein E, Hamilton R, Zucker N, Levitas A, Gross GJ. Presentation, natural history, and outcome in children and adolescents with double orifice mitral valve. Am J Cardiol 2004;93:1067-9.

4. Warnes C, Somerville J. Double mitral valve orifice in atrioventricular defects. Br Heart J 1983;49:59-64. 